\title{
Special Issue on
}

\section{Services to Patrons with Print Disabilities}

he ARL Joint Task Force on Services to Patrons with Print Disabilities released this report to bring much-needed attention to the challenges of print-disabled individuals who are seeking access to both print and digital library products and services. Print disabilities prevent some users from effectively reading information resources because of visual, physical, perceptual, developmental, cognitive, or learning disabilities. The task force expands upon the ongoing work of the Library Copyright Alliance in support of an international instrument for the print disabled that is under active consideration by the World Intellectual Property Organization (WIPO). It also brings attention to the growing demand for instructional e-content and burgeoning digital library collections and the opportunities for collaboration among university leadership, research libraries, disability services, and information technology services.

The report contains nine recommendations for research libraries to make information accessible to their full range of diverse users equitably. In particular, the report focuses on critical partnerships necessary to fully exploit the opportunities of digital information resources to open an unprecedented quantity of information to print-disabled patrons. The report also includes practical recommendations for individual institutions to improve responsiveness and In This Issue organizational capacity to address the needs of this community more effectively. ARL believes that research libraries are poised to provide critical direction-along with academic leadership, IT, and disability serviceson the service and technology planning, procurement, and licensing necessary to create a fully accessible information environment.

Members of the task force were Mary Case (Illinois at Chicago), Chair; Cynthia Archer (York); Nancy Baker (Iowa); Will Cross (North Carolina State); John Harwood (Penn State); Sarah Hawthorne (California, Berkeley); Kurt Herzer (Johns Hopkins); Tito Sierra (MIT); Ed Van Gemert (Wisconsin-Madison); Tom Wall (Boston College); Prue Adler (ARL); and Judy Ruttenberg (ARL). Howard P. Knopf, Counsel, Macera \& Jarzyna/Moffat \& Co.,

Executive Summary.

Print Disabilities, Libraries, and

Higher Education.

US and Canadian Disability Policies, Recent Challenges, and US and Canadian Copyright Law. 10

Research Libraries and Individuals with Print Disabilities.

Universal Design, Inclusive Design, Accessibility, and Usability...........25

Conclusion. 28

Appendix A: Model Licensing University, assisted in framing the copyright discussions of the report. 


\section{Executive Summary}

R

esearch libraries have a responsibility to make library collections and services universally accessible to their patrons. Doing so is consonant with research library community values and is also necessary in order to comply with long-standing legal requirements. The role of research libraries has changed dramatically with the adoption of information technologies and network-based services, and these technologies are similarly transforming education at all levels.

Both the utilization of these technologies and the digital revolution in publishing have been key drivers in transforming research libraries and their role in the teaching and research ecosystem. IT, networked services, and digital publishing have also spurred access to the growing corpus of digital resources. And as research libraries provide more content electronically to students, faculty members, researchers, and others, the role of libraries and other partners in their institutions and beyond is changing in the provision of information resources and services to patrons with disabilities. Whereas in the past, institutional offices of disability services were the primary facilitators of access to needed research resources and instructional materials, increasingly, the digital environment requires research libraries to be full partners with disability services offices and IT departments to ensure that these electronic resources, when acquired, are fully accessible to all members of the campus or research library community. Within this nexus of actors in ARL institutions, the library has both the mission and capacity to provide leadership on matters of content and the depth of experience to provide services to the entire institutional community.

This ARL task force report focuses on issues relating to users and members of the research library community who are print disabled. ${ }^{1}$ Research libraries serve a user community with a diverse set of disabilities every day, and this report is a starting point to address issues and opportunities of accessibility more broadly.

Over the last two years, there have been a growing number of complaints filed by print-disabled individuals in academic and non-academic institutions in the US regarding use of inaccessible IT products and services. These include settlements with Case Western Reserve University, Reed College, Pace University, Arizona State University, Princeton University, and the Darden School of Business at the University of Virginia regarding inaccessible e-readers; a voluntary agreement between the National Federation of the Blind (NFB) and Penn State University to make university services more accessible, prompted by a US Department of Education Early Complaint Resolution process; a voluntary agreement with Florida State University to make some courses more accessible; a settlement with the Free Library of Philadelphia regarding use of inaccessible e-readers; and a settlement agreement between the US Department of Justice and the Sacramento Public Library regarding inaccessible e-readers. Settlements have favored those filing the complaints.

There are several outstanding challenges, such as the recent initiation of an investigation by the Department of Education into accessibility concerns at the University of Montana, which includes a focus on access to library services; and correspondence between the NFB and EDUCAUSE/Internet2, Courseload, and McGraw-Hill Education, in which the NFB states that the EDUCAUSE/Internet2 e-textbook pilot violates both the Americans with Disabilities Act (ADA) and guidance from both the Departments of Justice and Education. Discussions are now underway between the NFB, Internet2, and 
EDUCAUSE. It is likely that more challenges will be forthcoming, given the tension between rapidly changing IT products and services and the need to ensure accessibility to these information services and resources for all members of academic and research community.

There is a growing sense of urgency regarding how best to effectively address these technologybased accessibility challenges in research libraries and in the broader institutional setting. The common practice today is to "fix after the fact," either through scanning and editing printed materials as needed or retrofitting an online service or product well after adoption. This approach is costly for both the library and the institution, and it is not fully effective for individuals with disabilities. Moreover, this approach does not scale to the digital environment. New strategies are required.

In May 2012, ARL formed a Joint Task Force on Services to Patrons with Print Disabilities, sponsored by two of ARL's strategic directions, Influencing Public Policies and Transforming Research Libraries. This task force was established to expand upon the ongoing work of the Library Copyright Alliance (LCA), of which ARL is a member, in support of an international instrument for the print disabled that is under active consideration by the World Intellectual Property Organization (WIPO). ${ }^{2}$

This ARL task force report highlights emerging and promising strategies to better align research libraries with other institutional and related partners in ensuring accessibility to research resources while fully meeting legal requirements. The report addresses the technological, service, and legal factors relating to a variety of information resources with respect to print disability. These factors resonate closely with the existing research library agenda to make scholarly communication more open, to foster independence among its user base by teaching information literacy, to honor and invest in diversity, as well as to focus on the growing trend toward universal design in instruction.

\section{Findings}

- The numbers of students with disabilities in post-secondary education is growing and includes diverse populations such as returning veterans.

- In the US, there are a number of laws that are the basis of federal policy for persons with disabilities, including the Americans with Disabilities Act of 1990, Section 504 of the Rehabilitation Act of 1973, and a 1998 amendment to the Rehabilitation Act (Section 508). Combined, these statutes and amendments ensure accessibility for individuals with disabilities to public accommodations, services, employment, and more.

- In Canada, accessibility law is under provincial or state jurisdiction. There is no national legislation specific to the area of accessibility. Therefore, practices supporting people with disabilities may vary from province to province.

- The US Department of Justice (DOJ) Civil Rights Division and the US Department of Education (ED) Office of Civil Rights share oversight and enforcement of legal provisions relating to individuals with disabilities at colleges and universities. In this role, ED and DOJ issued guidance to colleges and universities in 2010 stating that all programs, including pilot programs, are fully subject to the nondiscrimination requirements of the ADA and Section 504, including "ensuring equal access to emerging technology."3

- Retrospective print library collections and prospective digital library resources require very different strategies to achieve accessibility for patrons with print disabilities. 
- E-book accessibility may involve as many as three different considerations: the accessibility of the content, the accessibility of the reading platform, and the accessibility of the device.

- Most of the user-facing adaptive technology tools require electronic text to be properly encoded for the tool to work. It is this basic requirement that is the greatest barrier to making print library collections and library-mediated digital resources accessible.

- The US Copyright Act recognizes the importance of making works accessible and provides several specific exceptions that support library efforts to create derivative works for this purpose, including section 107 (fair use), section 110(8) (certain performances and displays) and section 121 (Chafee Amendment). A recent court decision, The Authors Guild, Inc., et al., v. HathiTrust, et al., strongly affirms that libraries may rely upon fair use and the Chafee Amendment of the Copyright Act to make works accessible.

- Recently, there have been positive updates to Canadian copyright law, the Copyright Modernization Act, regarding educational use in general and accessibility in particular. Provisions in the act will make the following changes, according to the Library of Parliament summary: the bill provides "amendments to the exceptions available to educational institutions, libraries, museums, archives and persons with a 'perceptual disability' in order to facilitate the use of digital technologies and make the provisions more technologically neutral."4

- Content provided by libraries is increasingly acquired digitally through a license that provides specific terms of use. These terms may significantly limit libraries' ability to make materials accessible-including journals, databases, e-books, and online textbooks-as accessibility features may not be built into the vendor platform or the terms and conditions of the license.

- Universal design in instruction or learning (UDI or UDL) recognizes that designing the classroom for maximum inclusion of diverse learning styles and abilities, without sacrificing either standards or aesthetics, will bring unanticipated benefits to the entire population served.

- Studies have demonstrated that, in addition to being more sustainable, integrated accessibility features are also far less costly in the long run. Moreover, there are many instances of accessible technologies leading true innovation and widespread adoption, "including the typewriter, the telephone, email, the PDA, speech synthesis and recognition. These innovations resulted from the need to meet accessibility needs of individuals." ${ }^{5}$

\section{Recommendations}

- The growing demand for instructional e-content and burgeoning digital library collections requires greater collaboration amongst all institutional partners, including academic leadership, research libraries, disability services, and information technology services. These partners should share knowledge, define roles, and become knowledgeable about print disabilities, in order to effectively serve users, to meet the requirements of federal and provincial law, to fulfill mission, and to move the market.

- Members of the research library community should collaborate within each institution and actively participate in cross-institutional and cross-industry efforts to advance universal design standards for digital information resources, library-mediated or otherwise. Such collaboration will also be most cost effective in acquiring accessible information products and services. 
- Research libraries should institute a plan to make all future websites, pages, and documents accessible while tackling older web resources over time.

- Universal accessibility should be embedded in future licensed and acquired products and services so special conversion to a usable format will only be required for retrospective works. With born-digital texts, e-readers, and other mobile devices, research libraries should advocate for accessible solutions up front-born-accessible materials-obviating the need for resourceintensive reformatting and retrofitting. Accessibility should be a central decision factor in choosing information products and services. Such an approach will meet both mission and the law.

- Accessibility and universal design considerations should be integrated into the library's technology planning and procurement processes. New technology-based library services should be evaluated for accessibility standards.

- Licensing must be done deliberately to protect the values and meet the legal requirements of accessibility, particularly in light of libraries' increasing reliance on licensed content in the digital environment. Research libraries should negotiate for more favorable terms in order to permit broader latitude to adapt content to meet the needs of patrons. With copyrighted works, research libraries should aggressively assert fair use in support of accessible services for the print disabled.

- Research libraries should have user-focused policies and procedures for patrons with disabilities that are readily available and kept up to date; accessibility service awareness needs to be a standard part of staff training.

- Research libraries should designate a liaison librarian who can provide or coordinate library assistance for users in partnership with the institution's disability services office and central IT. Research libraries should also provide professional development for all staff to better understand disabilities, including learning disabilities.

- Research libraries should identify a point person to partner with institutional assistive technology experts and information technologists to monitor trends and developments in this area on an ongoing basis, such as conducting usability testing with disabled students, faculty, and staff as well as helping to guide the organization's efforts to provide universal access for library collections and services. Similarly, this team should work with legal services and stay up to date on legal developments and best practices so that licensing and fair use determinations reflect current practice. 


\section{Print Disabilities, Libraries, and Higher Education}

$\mathrm{n}$ the United States, library services for the blind began in the 19th century, in the large public libraries of Boston, Chicago, New York, Philadelphia, and Detroit. In 1931, the Pratt-Smoot Act established the National Library Service for the Blind and Physically Handicapped through the Library of Congress. ${ }^{6}$ The Canadian Free Library for the Blind was established in Toronto in $1906 .{ }^{7}$

The universe of publishing consisted of printed books, magazines, and journals, and only a small percentage of that annual output was made accessible first in braille and later in "talking books." Blind readers, well aware of the inherent limitations of the printed page and the resources required to reformat it into braille or performed audio, refer to the era of print publishing as a "book famine." The digital revolution in publishing, including electronic texts, was supposed to end that famine-as electronic texts could, in theory, be processed directly by adaptive technologies designed to serve the print disabled. But an analysis of information technology and digital publishing instead tells a mixed story of progress and regress, of decentralization, lack of industry standards, and a host of reasons why, in 2012, advocacy for technological accessibility for the print disabled is urgent.

A print-disabled person is someone who cannot effectively read print because of a visual, physical, perceptual, developmental, cognitive, or learning disability. The definition and measurement of "learning disability" entered the educational parlance in the 1960s, and the US government increased funding for K-12 resources to address this growing concern. By the 1970s, this newly identified population began to enter colleges and universities. The Rehabilitation Act of 1973, as amended, established nondiscrimination requirements for all entities receiving federal funds, and in 1977, a critical mass of campus entities serving students with a range of disabilities formed a national association, the Association of Higher Education and Disability (AHEAD), establishing professional and service standards. ${ }^{8}$ The world of higher education, at this point, consisted of physical structures to be navigated, traditional classroom instruction to be effectively conveyed and captured, and printed texts to be studied.

In 1990, a new social and cultural vision of disability and public participation was expressed and compelled by the ADA. Inclusion and mainstreaming prevailed in K-12 special education, and that population entered colleges and universities in the 1990s and 2000s. ${ }^{9}$ In the still largely analog world of 1990, most books were not available in formats accessible to the blind. Assistive and adaptive technologies to reformat printed text emerged and made a great impact.

\section{SIDEBAR: ADAPTIVE TECHNOLOGY FOR PRINT DISABILITIES}

Adaptive technology, also known as assistive technology, refers to a wide variety of tools to help people with disabilities. The adaptive technology needs of print-disabled users vary. Tools used by the blind differ from those with severe or moderate vision impairment. The adaptive technology for compensating for visual impairments can take a variety of forms and typically utilize a combination of technologies. Below are examples of some of the most common building-block technologies used in adaptive technology tools to address visual impairments. 
- Digital Scanning-Computer hardware and software to convert printed material to digital form.

- Optical Character Recognition (OCR) - The process of converting printed characters from a digital scan into machine-readable electronic text.

- Synthesized Speech-A computerized audio representation of human speech used to read aloud text and describe visual elements.

- Text-to-Speech (TTS)-The computerized process of converting electronic text into synthesized speech.

- Braille Translation Software-Software that converts printed text into braille cells.

The specific user-facing adaptive technology tool or tools used by a person with print disabilities will vary based on a variety of factors, including access to tools, training and support in the use of these tools, as well as personal preference. Most of the user-facing adaptive technology tools, outlined below, require electronic text to be properly encoded for the tool to work. It is this basic requirement that is the greatest barrier to making print library collections and library-mediated digital resources accessible.

Examples of the most commonly used adaptive technology tools are:

- Screen Magnifier-Hardware or software that enlarges the display of a computer screen.

- Screen-Reader Software-Software that provides voice output for items displayed on a computer screen. Unlike a pre-recorded audio book, this software facilitates independent navigation through the content and enables users to read text at their preferred speed. It also has the capacity to allow the reader to get structural information, such as punctuation and paragraphing through differential pauses and to move, when necessary, character by character to learn the spelling of a given word.

- Scan-and-Read Software-Software that converts a printed document to electronic text using a combination of digital scanning, optical character recognition software, and synthesized speech.

- Braille Embosser-A specialized printer that produces tactile braille cells, typically using input from braille translation software.

- Refreshable Braille Displays-An electro-mechanical device for displaying braille characters.

Adaptive technologies opened new doors to people with print disabilities and raised their expectations about information access. In an open letter to President Clinton in 2000, university presidents recognized the importance of making information and communications technologies more accessible for individuals with disabilities and noted that "people with disabilities will find it much easier to live, learn and work as they enter the Information Age."10

On college and university campuses, libraries were in some cases early partners in providing these services, spaces, and equipment, but this function was still seen as the responsibility of disability services offices. It was those offices that offered reformatted, accessible textbooks and other classroom materials to their registered students and who later worked with publishers to receive born-digital files to distribute to students. 
Against the backdrop of this recent history and set of campus dynamics, information technology and digital publishing exploded, and research libraries found themselves transforming their role in research, teaching, and learning. Research libraries occupy a unique space in these transformative times-as stewards of long-held, carefully built print collections and as partners in the emerging cyberinfrastructure that propels and sustains e-research. In the past decade, research libraries have collectively digitized millions of print volumes, moved collection expenditures decisively from print to electronic resources, and invested in a range of desktop and mobile technologies for accessing and manipulating both print and electronic information for diverse user populations. Research libraries now have a central role to play in the digital age in providing equitable access to information resources to their users. This report will highlight emerging and promising strategies to meet this goal of enhancing access to the print disabled.

Research library investments in digital content have ranged from locally built websites to commercially licensed electronic databases, online catalogs, e-journals, and e-books. The marketplace of digital educational goods and services has opened some doors of accessibility while closing others. This report will address the technological, legal, and service factors in research libraries with respect to print disability. These factors resonate closely with the existing research library agenda to make scholarly communication more open, to foster independence among the user base by teaching information literacy, to honor and invest in diversity, as well as to focus on the growing trend toward universal design in instruction. Libraries thus provide a basis for ongoing and new partnerships and collaboration both inside and outside of individual institutions.

Just as the ground has shifted for research libraries with respect to their responsibilities to the printdisabled community, so too has the ground shifted for disability services offices, who have from the outset been in the business of accommodations and individualized, specialized attention for students with disabilities. The concept of born-accessible materials is a key solution to an IT landscape that includes new players and new roles across the entire research institution.

In 2011, researchers at the University of Maryland posed the inclusion challenge to a range of institutional actors:

Educators that work with students training to become developers-such as computer science faculty — could work to better incorporate accessibility into curricula, so that all developers are prepared to make accessible products and understand that accessibility is the socially responsible approach to development. Researchers in fields related to accessibility - such as computer science, information science, sociology, public policy, and communication - could also better support a culture of online accessibility by producing more research to contextualize the impacts of inaccessibility on people with disabilities, to support the development of accessible products, and to study policy options related to accessibility. ${ }^{11}$

Research libraries occupy a distinctive position in that they have multi-level relationships with a wide range of institutional entities. Working with content creators-such as faculty or other researchersto use available accessibility features of authoring software in their own work could be an excellent opportunity for library outreach, engagement, and expertise. 


\section{Print Disabilities and the Population}

The US Government Accountability Office has shown that the numbers of students with disabilities in post-secondary education is growing-with marked increases in cognitive disabilities such as dyslexia and autism, and growing populations such as returning veterans. ${ }^{12} \mathrm{~A}$ Canadian government survey of 2006 found that disability among children had increased since 2001. Among Canadian children aged 5 to 14 that increase was from $4 \%$ to $4.6 \%$. With regard to special education services, parents reported learning disabilities as the most likely reason their children were receiving services. ${ }^{13}$

The population of the print disabled is both significant and growing. The Reading Rights Coalition estimates that there are "30 million Americans who cannot read print because of blindness, dyslexia, spinal cord injury, and other print disabilities." ${ }^{14}$ Notably, vision loss can be a consequence of other growing health concerns, such as diabetes, which increasingly affects people of all ages. Moreover, research libraries serve patrons of all ages, including students, faculty, staff, and alumni. According to the National Institutes of Health,

With the aging of the population, the number of Americans with major eye diseases is increasing, and vision loss is becoming a major public health problem. By the year 2020, the number of people who are blind or have low vision is projected to increase substantially...Blindness or low vision affects 3.3 million Americans age 40 and over, or one in 28...This figure is projected to reach 5.5 million by the year $2020 .{ }^{15}$ 


\section{US and Canadian Disability Policies, Recent Challenges, and US and Canadian Copyright Law}

$\mathrm{n}$ the US, there are a number of laws that serve as the basis of federal policy for persons with disabilities. These include the ADA of 1990, Section 504 of the Rehabilitation Act of 1973, and a 1998 amendment to the Rehabilitation Act (Section 508). Combined, these statutes and amendments ensure accessibility for individuals with disabilities to public accommodations, services, employment, and more. In addition to federal law, many states have implemented accessibility statutes and regulations.

The ADA mandates the elimination of discrimination on the basis of disability. Titles I, II, and III of the ADA prohibit discrimination against individuals under certain circumstances. Title I prohibits discrimination in public and private employment against individuals with disabilities. Title II of the ADA provides individuals with disabilities with an equal opportunity to benefit from all state and local government programs, services, and activities. Finally, Title III prohibits discrimination against individuals with disabilities regarding the "full and equal enjoyment of the goods, services, facilities, privileges, advantages, or accommodations" of any public accommodations, including private, postsecondary institutions. Thus, research libraries in public and private institutions must comply with selected ADA provisions.

Section 504 of the Rehabilitation Act of 1973 prohibits discrimination on the basis of disability in programs and activities by those entities that receive federal financial assistance. Pell Grants and Federal Work Study grants are examples of federal assistance via the Department of Education relating to higher education.

Finally, Section 508 of the Rehabilitation Act Amendments of 1998 relates to access to federally funded programs and services. The amendment requires that the electronic and information technologies that an agency develops, procures, maintains, and/or uses must be accessible to federal employees and all members of the public. Since Section 508 was enacted, 20 states have enacted similar laws and requirements.

The US Department of Justice (DOJ) Civil Rights Division and the US Department of Education (ED) Office of Civil Rights share oversight and enforcement of legal provisions relating to individuals with disabilities at colleges and universities. For example, the DOJ is responsible for enforcement of Title III of the ADA relating to private universities and colleges, and both departments jointly enforce legal requirements under Title II of the ADA applicable to public universities; additionally, ED oversees Section 504 regarding public and private educational institutions that receive financial aid from the Department of Education. Finally, the Institute of Museum and Library Services (IMLS) issued guidance "Making Museums and Libraries More Accessible“ in February 2011. ${ }^{16}$

\section{Recent Challenges to Institutional Practices}

Over the last two years, there have been a growing number of complaints filed by print-disabled individuals in academic and non-academic institutions regarding use of inaccessible IT products and services. Settlements have favored those filing the complaints. There are several outstanding challenges, and it is likely that more will be forthcoming, given the tension between rapidly changing IT products 
and services and the need to ensure effective access to information services and resources for all members of the academic and research community. ${ }^{17}$

In 2010, the US Departments of Justice and Education entered into settlement agreements and/or letters of resolution with a number of academic institutions regarding accessibility and use of e-readers in the classroom. Case Western Reserve University, Reed College, Pace University, Arizona State University, and Princeton University participated in pilot projects with Amazon.com to test the value and utility of using the Kindle DX in a classroom setting. The DOJ determined that the Kindle DX was "inaccessible to an entire class of individuals with disabilities—individuals with visual impairments." ${ }^{18}$

In the settlement agreements, the academic institutions agreed to only purchase e-readers that were fully accessible to individuals with visual impairments or provide "reasonable modification for this type of technology."19 Reasonable modification, in this instance, is defined as changes so that "blind individuals may access and acquire the same information, engage in the same interactions, and enjoy the same services as sighted students with substantially equivalent ease of use." ${ }^{20}$ The Departments of Education and Justice also entered into an agreement with the University of Virginia Darden School of Business regarding its use of the Kindle DX. It is important to note that ED and DOJ issued guidance to colleges and universities stating that all programs including pilot programs are fully subject to the nondiscrimination requirements of the ADA and Section $504 .{ }^{21}$

Students and other members of the campus community can raise accessibility concerns via the ED's Office of Civil Rights, through the DOJ, or locally within their own institutions. For example, a student at the University of California (UC), Berkeley, recently raised accessibility concerns regarding scanning technology in the library. This led the campus to enter into a structured negotiations process with a disabilities rights organization, Disability Rights Advocates, to cooperatively resolve many cutting-edge print access issues, including the question of the University Library's responsibilities to make its large collection of hard-copy bound books accessible to those with print disabilities—specifically, the degree to which the library will convert hard-copy print into a digital format. Traditionally, some campuses have relied upon the disability services office to convert books needed by students with print disabilities doing library research for a course assignment or even for a graduate thesis. Of necessity, this has limited the number of books converted to a relative few, compared to the vast resources of a research library.

In another instance, following five years of campus discussions, the Alliance for Disability and Students at the University of Montana (ADSUM) filed a complaint with ED alleging that some disabled students at the university face discrimination, as educational technologies are not accessible. In August 2012, the ED confirmed that it is investigating the complaint and is focused on the following services: inaccessible class assignments and materials in the learning management system, Moodle; inaccessible live chat and discussion board functions in Moodle; inaccessible documents that are scanned images on webpages and websites; inaccessible videos, and videos in Flash format, that are not captioned; inaccessible library database materials; inaccessible course registration through a website, Cyber Bear; and inaccessible classroom clickers. ${ }^{22}$

In November 2010, as a part of the ED's Early Complaint Resolution process, Penn State University and the NFB entered into a voluntary agreement to ensure that all electronic and information technology systems used on all Penn State campuses be fully accessible to blind students, faculty, and staff. Information technology services include course management systems, websites, classroom technology, 
library resources, banking services, and more. The agreement is comprehensive, and it includes accessibility goals to be achieved within certain timeframes, that members of the university community be educated regarding print-disability issues, and that accessibility must be addressed in all campuswide information technology procurement. ${ }^{23}$ The agreement serves as a model for other colleges and universities. Indeed, setting precedent for other academic institutions was a stated goal of the NFB in reaching this agreement.

Similarly, based on complaints by two print-disabled students, Florida State University agreed to make a number of its science and math courses more accessible, as the students were unable to complete courses related to their academic track.

In response to the growing number of e-reader pilot programs and the development and adoption of IT services at colleges and universities throughout the US, the Departments of Education and Justice issued a joint "Dear Colleague Letter" to college and university presidents. ${ }^{24}$ The letter stated that use of information technologies such as e-readers-both existing and emerging-must be accessible to students with disabilities, or institutions would risk violating the ADA and Section 504 unless other accommodations or modifications could be made to allow these students to "receive all the educational benefits provided by the technology in an equally effective and equally integrated manner." 25

The authors of the letter to the presidents stated, "[w]e ask that you take steps to ensure that your college or university refrains from requiring the use of any electronic book reader, or other similar technology, in a teaching or classroom environment as long as the device remains inaccessible to individuals who are blind or have low vision. It is unacceptable for universities to use emerging technology without insisting that this technology be accessible to all students." ${ }^{26}$ In a subsequent FAQ to presidents of colleges and universities (May 2011), ED reiterated that "equal access for students with disabilities is the law and must be considered as new technology is integrated into the educational environment." ${ }^{27}$

In September 2012, the President of the NFB, Marc Maurer, wrote to the presidents of Internet2, EDUCAUSE, McGraw-Hill Education, and the CEO and founder of Courseload concerning a joint EDUCAUSE/Internet2 e-textbook pilot. The pilot seeks to advance a new model for the purchase, distribution, and use of e-textbooks and digital course materials. Twenty-five academic institutions are participating in the pilot in the current academic semester (fall 2012), with expansion anticipated in the spring of 2013. In his letter, Maurer noted that, "although we support the use of e-textbooks at colleges and universities, we are shocked and dismayed that you are moving forward with the program without first correcting the obvious accessibility barriers that prevent blind students from participating." ${ }^{28} \mathrm{He}$ further noted that the program "in its current form does not meet the participating schools' obligation under ADA and Section 504." Maurer asked that the pilot not continue until accessibility issues were resolved. In response, the presidents of EDUCAUSE and Internet2 noted that "recognizing the pace of change in technology, and specifically in outside tools has dramatically increased, the only way to identify challenges and make progress is by assessing tools and materials that may not yet be mature." They indicated their intention to "build on these results and more to deploy a diverse set of pilots involving several e-reader platforms and several publishers" in the spring of $2013 .{ }^{29}$ Developments are ongoing as of the writing of this report and further conversations amongst the groups are underway. 


\section{AIM Commission}

In 2011, the Advisory Commission on Accessible Instructional Materials in Postsecondary Education for Students with Disabilities (AIM Commission) released a report to Congress that focused on improving access to instructional materials for students with disabilities in a timely and cost-effective manner. ${ }^{30}$ Key findings include:

- Students with disabilities, and most notably students with print disabilities, often experience a variety of challenges that result from inaccessible learning materials and/or their delivery systems.

- Disability resource service providers and other university personnel often must engage in laborintensive practices to provide accessible instructional materials to students with disabilities.

- Textbook publishers and a number of electronic text vendors are moving to incorporate accessibility into their products, but many products are still inaccessible to students with disabilities who have difficulties accessing printed text.

- Opportunities for capacity building within postsecondary educational institutions are essential for improving the ability of these institutions to provide accessible instructional materials to students with disabilities.

Key recommendations of AIM include:

- Congress should authorize the United States Access Board to establish guidelines for accessible instructional materials that will be used by government, in the private sector, and in postsecondary academic settings.

- Congress should review the scope, effectiveness, and function of the Copyright Act as amended (section 121, the Chafee Amendment) to determine whether it or any of its key component elements, as well as its implementation through applicable regulations, need to be updated to adequately address the needs of individuals with print disabilities, including those enrolled in postsecondary education.

- Congress should consider incentives to accelerate innovation in accessibility by publishers and producers of course materials, hardware, and software by offering support and inducements for the production, sale, and consumption of accessible instructional materials and delivery systems.

- The commission recommends that federally sponsored projects and programs encourage and support systematic faculty and staff professional development with respect to selection, production, and delivery of high-quality accessible instruction materials to meet the needs of students with disabilities in postsecondary settings.

\section{US Copyright Law and Issues for Print-Disabilities Services}

Libraries have important policy commitments and substantial legal obligations to make materials fully accessible to patrons. Until recently, copyright law presented challenges for libraries seeking to provide full access to materials because some believed that it did not allow copying and modification of existing works without permission. As a result, there has been tension between copyright law and effective library access for those with print disabilities. Solutions to this tension are based on the exceptions built into the Copyright Act. Indeed, a recent court decision, The Authors Guild, Inc., et al., v. HathiTrust, et al., declared 
expressly that Section 107 of the Copyright Act, fair use, is available to resolve the apparent tension between copyright and accessibility (see next section for details about this court decision).

The Copyright Act recognizes the importance of making works accessible and provides several specific exceptions that support library efforts for this purpose: Sections 107, 110(8), and 121.

The primary copyright exception in this area is Section 121 of the Copyright Act, often called the "Chafee Amendment," which permits copies of previously published, nondramatic literary works to be translated into "braille, audio, or digital text" and distributed to individuals with specified disabilities. ${ }^{31}$ Many established formats for disabled patrons, such as large-print books, are not included. This privilege is qualified by several important limitations regarding the type of use, the items that may be copied, and the institutions that are authorized to create these translations.

Copies under the Chafee Amendment can only be made by an authorized entity—a government agency or a nonprofit organization that has a "primary mission to provide specialized services relating to adaptive reading or information access needs." Many libraries and other organizations believe that providing services to the print disabled is a primary mission and thus have been serving the printdisabled community. The ruling in The Authors Guild, Inc., et. al., v. HathiTrust, et. al. fully supports this view. As stated by Judge Baer, "The ADA requires that libraries of educational institutions have a primary mission to reproduce and distribute their collections to print-disabled individuals, making each library a potential 'authorized entity' under the Chafee Amendment." ${ }^{\prime 32}$

Libraries also rely on partnerships with other authorized institutions, such as the National Library Service Program, Learning Ally (formerly Recordings for the Blind and Dyslexic), State and Regional Libraries for the Blind, Bookshare, and the American Printing House for the Blind. ${ }^{33}$

Finally, the Chafee Amendment clearly delineates which patrons may avail themselves of copies made under this exception. Copies may only be distributed to "individual(s) with a disability" who are certified by a competent authority as unable to read normal printed material as a result of physical limitations. Library of Congress regulations—described in 36 CFR 701.6(b)(1) \& (2)—explicitly define the types and degree of disability as well as the particular bodies that qualify as "competent authority" to certify disabled individuals. Disabled patrons who have not been certified by one of the authorities named in the law may not access copies made under Chafee.

Overall, the Chafee Amendment provides an important exception to copyright's limitations on copying, but some believe it offers insufficient latitude to support libraries' efforts to fully serve all patrons and meet their legal obligations.

The Copyright Act provides another exception for libraries: 17 U.S.C. \$110(8) permits "performance of a nondramatic literary work, by or in the course of a transmission specifically designed for and primarily directed to" patrons who are unable to "read normal printed material" or "hear aural signals" as a result of their disability. ${ }^{34}$ These transmissions must be "made without any purpose of direct or indirect commercial advantage" and made available through the facilities of a government body, a noncommercial educational broadcast station, or a narrowly defined set of broadcasters. This permits qualifying libraries to stream content directly to patrons with disabilities in these limited situations.

Copyright law also provides a general exception for socially valuable uses. Fair use may support copying to "fill the gap" in cases where copying benefits society and where the market is not reasonably providing necessary services. A claim of fair use is evaluated based on the statutory factors described in 17 U.S.C. $\S 107$, including the following: (1) the purpose and character of the use, including whether such 
use is of a commercial nature or is for nonprofit educational purposes; (2) the nature of the copyrighted work; (3) the amount and substantiality of the portion used in relation to the copyrighted work as a whole; and (4) the effect of the use upon the potential market for or value of the copyrighted work. ${ }^{35}$

Fair use is a fact-specific analysis that weighs all four factors. Fair use generally privileges nonprofit efforts that do not disrupt existing markets, so library services that do not compete with services offered by rightsholders may be strong candidates for a claim of fair use. Indeed, the Code of Best Practices in Fair Use for Academic and Research Libraries expresses the consensus of academic and research librariansproviding accessible material is likely to be fair, particularly when tailored to the specific needs of the patron. ${ }^{36}$ The fair use case is strongest when efforts are coordinated with the university's disabilities services office, which works with individuals entitled to service, informs them of their rights and responsibilities, and adopts policies that are widely and consistently applied. The combination of the Chafee Amendment and fair use generally provides sufficient latitude to overcome any concerns about possible institutional risk in order to best meet mission and serve the needs of the print-disabled community. As noted by Judge Baer in the recent ruling concerning HathiTrust, "I cannot imagine a definition of fair use that would not encompass the transformative uses made by the Defendants' MDP [Mass Digitization Project] and would require that I terminate this invaluable contribution to the progress of science and cultivation of the arts that at the same time effectuates the ideals espoused by the ADA." ${ }^{37}$

Libraries can also seek permission for specific uses from the rightsholder. Because there can be tens or hundreds of individual rightsholders who must be contacted, however, transactional costs present a major barrier to large-scale efforts. Libraries may mitigate these costs by leveraging their partnerships and collaborative networks as well as their expertise and experience with licensing.

\section{Authors Guild v. HathiTrust Litigation}

The recent landmark decision in The Authors Guild, et. al., v. HathiTrust, et. al., litigation provides important guidance on key legal questions around accessibility. For several years, the HathiTrust Digital Library (HDL) and its member libraries have worked to index and preserve digitized works from library collections to foster research, teaching, and learning. The Authors Guild (AG), with other associations and a handful of individual authors, sued HDL claiming that its mass digitization program, in collaboration with Google, constituted copyright infringement. The Library Copyright Alliance filed two amicus briefs in this case in support of HDL. The NFB and three individuals with print disabilities intervened in the case. In its brief before the District Court for the Southern District of New York, the NFB noted, "without the HDL, the blind are relegated to second-class academic citizenship-one without the privilege of access to the print collections of university libraries. With the HDL, the blind have the same comprehensive access to the print collections of university libraries as the sighted, and as a result, can learn and contribute to learning as do sighted students and scholars." ${ }^{\prime 38}$

On October 10, 2012, Judge Baer of the US District Court for the Southern District of New York ruled in favor of HDL and the NFB. First, the court held that fair use is a supplement to Section 108, and, contrary to the AG's arguments, libraries are entitled to a full fair use defense and are not required to rely only on Sections 108 and 121 to preserve and provide access to library collections. ${ }^{39}$ Second, the court held

that mass digitization for search, preservation, and accessibility is a fair use and two of HDL's purposes (search and accessibility) are "transformative," because the works are used for a different purpose from 
the original, intended purpose. The court found that use of the entire work is fair where appropriate to the purpose. Moreover, the court pointed to evidence showing that a market likely could not develop for licensing these kinds of uses, and that further, because they are transformative, these uses cannot be subject to licenses. The ADA requires, and fair use and the Chafee Amendment allow, digitization for accessibility.

Finally, the court determined that making library collections equally accessible is required for equal access to education for the print disabled. The market will not satisfy the need. The court found that the Chafee Amendment applies because the ADA makes accessibility a "primary mission" for all libraries. And Judge Baer noted that even if the Chafee Amendment does not apply, fair use does. This landmark ruling is powerful evidence that the law will strongly favor libraries when they do what is necessary-up to and including digitizing millions of books-in order to provide equitable access to materials.

This decision presents many opportunities for research libraries. For example, the decision strongly suggests that research libraries now may retain scanned, digital copies that were previously made available to a disabled student and make them available to other print-disabled students. Retention of these copies for that purpose constitutes a fair use. In addition, once a research library or disability services office makes a scanned copy of a work under the Chafee Amendment, the print disabled at other institutions may use this copy, rather than duplicate the scanning effort. Moreover, if vendors and publishers do not provide works in an accessible format to the research library, fair use entitles the library to make these resources accessible. Finally, the use of descriptive metadata to improve accessibility to the Hathi corpus, such as the labeling of images, will over time result in a more effective and higher quality search for all users.

\section{US Engagement with World Intellectual Property Organization (WIPO)}

The US government is participating in international discussions at the World Intellectual Property Organization (WIPO) in support of an international instrument for exemptions and limitations for the visually impaired. It is not clear if the "Working Document on an International Instrument on Limitations and Exceptions for Visually Impaired Persons/Persons with Print Disabilities" ${ }^{\prime \prime 0}$ will become a binding treaty or take another form of international agreement such as guidelines or recommendations known as "soft law." The Library Copyright Alliance, as a non-governmental organization represented at WIPO, is actively engaged in these discussions. A meeting in November 2012 is seen as central to determining the pace and progress of whether an international instrument will be completed in the near term. WIPO discussions typically take years to conclude, and this discussion concerning access to copyrighted works by the visually impaired has been under discussion since 2006.

\section{Disability and Copyright Law in Canada}

In Canada, accessibility law is under provincial or state jurisdiction. There is no national legislation specific to the area of accessibility. Therefore, practices supporting people with disabilities may vary from province to province. In Ontario, for example, academic institutions and libraries work under the Accessibility for Ontarians with Disabilities Act (AODA); whereas, in Saskatchewan, the Saskatchewan Human Rights Code, alongside the Canadian Charter of Rights and Freedom, is applied. 
Unlike accessibility law, copyright law is under federal jurisdiction. Copyright issues affecting persons with disabilities are dealt with solely at the federal level in the Copyright Act.

The Canadian copyright landscape has changed appreciably over the last six months. New copyright legislation was passed on June 29, 2012, and is known as Bill C-11, or the Copyright Modernization Act. As of October 16, 2012, the legislation awaits "proclamation" in whole or in part, which is expected at any time. In addition, the Supreme Court of Canada (SCC) made judgments in July 2012 on five simultaneous copyright decisions. A key point emerging from these decisions is that there is a far greater scope of fair dealing in the educational sector than the Copyright Board had recognized previously. The SCC ruled that the provision by teachers of multiple copies of short excerpts, and the making of copies of material prescribed by a teacher, may be fair; the purpose of the student is relevant.

Bill C-11 includes general provisions of interest regarding accessibility in addition to provisions solely focused on disabilities issues. The legislation provides that "organizations acting for the benefit of persons with a 'perceptual disability' can copy a work protected by copyright in alternate formats such as Braille, talking books or sign language."'41

Provisions in Bill C-11 will make the following three changes, according to the Library of Parliament summary. ${ }^{42}$ First, the bill provides "amendments to the exceptions available to educational institutions, libraries, museums, archives and persons with a 'perceptual disability' in order to facilitate the use of digital technologies and make the provisions more technologically neutral." ${ }^{\prime 43}$

Second, there are exceptions for persons with perceptual disabilities (sections 32 and 32.01 of the Act) and an exception for nonprofit organizations acting for the benefit of persons with a print disability to make a copy of a work in a format specifically designed for persons with a print disability. This includes the ability to send a copy of the work to similar organizations abroad, as long as the work being adapted is by a Canadian author or a national from the country to which the adapted work is being exported.

Finally, the liability of a nonprofit organization that makes a good-faith mistake regarding an author's nationality is limited. This amendment would clarify or would allow the courts to take into account goodfaith efforts taken by the nonprofit organization when awarding damages, and copyright owners would then be able to seek only an injunction against the nonprofit organization rather than damages.

\section{Licensing Issues}

Librarians seeking to provide accessible content for their patrons must also grapple with licensing, rather than purchasing, electronic content, thus licensing is important to ensuring accessibility. Since the growing adoption of e-journals in the 1990s, content provided by libraries is increasingly acquired digitally through a license that provides specific terms of use. This practice may significantly limit libraries' ability to make such materials as e-journals, databases, e-books, and online textbooks accessible, since accessibility features may not be built into the vendor platform or the terms and conditions of the license.

In cases where library materials are licensed, the terms of use may be governed by the private law agreement - the license-rather than simply by the public law of the US Copyright Act or Canadian copyright law. Although traditional copyright law remains the default in the absence of explicit language, the terms of a license can affect libraries' ability to make works fully accessible. 
As a result, carefully and deliberately negotiating these licenses is critical to making materials accessible. Terms limiting libraries' ability to copy and modify content may foreclose the ability to make accessible versions of library materials, compounding the issues described above. By the same token, however, more favorable terms may give libraries broader rights to adapt content to meet the needs of patrons. Libraries can require that any licensed content come with accessibility "baked in" (see Appendix A). Individual libraries and consortia must carefully strike this balance, as they have always done when acquiring content. 


\section{Research Libraries and Individuals with Print Disabilities}

esearch libraries acquire materials in many formats and aspire to make all of them discoverable and accessible to their many diverse constituents. Doing so is consistent with our professional values and legal requirements. To the extent that libraries have provided reformatting services (or partnered with other entities to do so) for large retrospective print collections "without undue burden" and/or "undue hardship" under the ADA for more than two decades, they should continue to optimize those processes and services. Research libraries are challenged to continue that access while expanding access to digital information resources in increasingly diverse formats. Ensuring that both print and digital versions are accessible to patrons with print disabilities requires different strategies for each format.

Technology considerations play a key role in making library collections and services accessible. The technology issues surrounding library services for patrons with print disabilities are diverse and evolving. Despite the challenges, library professionals need to stay well informed about the issues, monitor trends, and respond to opportunities for improving library services for this user group. This section of the report provides research library administrators and interested library professionals with an introduction to the major technology considerations involved in making library collections and services more accessible for patrons with print disabilities.

\section{Retrospective Print Collections}

The most common method for making retrospective print collections accessible to patrons with print disabilities is to combine digital scanning and optical character recognition (OCR) technology to reformat print source materials into electronic formats that can be "read" by user-facing adaptive technology tools. Many ARL member libraries currently provide "scan and reformat" services for patrons with documented print disabilities. The most common approach is to digitally scan the print material and covert it to PDF with embedded text for text-to-speech delivery on the user's preferred adaptive technology tool. Other output formats may include specialized electronic files (such as DAISY book format), braille documents, or tactile diagrams.

The typical reformatting workflow to convert printed work into an accessible digital format involves a sequence of technology-enabled and human-mediated steps. Below is an example workflow:

1. Capture a digital still image of a page using a digital photocopier, flatbed scanner, or specialized book scanner.

2. Run OCR software on the page image to automatically extract electronic text.

3. Repeat step 1 if the OCR process yields too many errors due to a poor-quality scan.

4. Repeat steps 1-3 for each page of text to be reformatted.

5. Ensure that the reading order is proper (if there are columns, footnotes, sidebars, etc.).

6. Edit the digital copy for OCR errors and add additional description, if needed.

7. Convert pages containing mathematical symbols to MathML using one of a number of open source or inexpensive programs.

8. Deliver a final digital copy of the text in the requested accessible format. 
Although advances in information technology have lowered the hardware and software costs for the overall reformatting process, this service still requires non-trivial equipment, training, and ongoing staffing costs. Staff time to edit reformatted documents can vary greatly depending on the source material and the level of quality control desired. Advances in book scanning technology show great promise in improving page scanning and OCR processing throughput. The UC Berkeley Library, for example, has recently acquired an Atiz scanner designed to quickly scan bound books without damaging the spine. The library estimates that such high-quality scanning, even without extensive staff editing and processing, will produce two errors per page or less. However, the high capital-equipment costs of purchasing such high-performance book-scanning equipment may be out of reach for some libraries.

\section{Licensed Electronic Resources}

Licensed electronic resources, such as e-journals, e-books, databases, online reference sources, and digital media collections, pose a different set of accessibility challenges, due to the diversity of digital content formats and delivery methods. Although accessibility standards exist for many digital content formats, content publishers do not always utilize them to maximum advantage.

Consider the case of electronic books. The current e-book technology landscape is rapidly evolving with many combinations of file formats, devices, and platforms. E-books are published in a variety of formats, some open and some propriety, with varying levels of support for accessibility. EPUB 3 is an example of an emerging standard that was developed from the ground up with accessibility for printdisabled users in mind. Open standards for digital content that incorporates accessibility features from the start are the clear path forward to making digital content broadly accessible.

In many cases, the library provides patrons with proxy access to licensed electronic resources that are hosted and delivered on a content provider's website. In this model, it may be logistically difficult, and in some cases technically infeasible, for the library to provide an alternative accessible copy or version of the resource if the resource itself was not properly encoded for accessibility from the start.

Under these circumstances, it is critical that libraries independently exercise their power as buying agents to improve the state of electronic resource accessibility. Libraries should require publishers and vendors to comply with legal requirements for accessibility (e.g., Americans with Disabilities Act, Section 508 of the Rehabilitation Act Amendments, state and provincial laws) and implement industry best practices for accessibility (e.g., World Wide Web Consortium [W3C] Web Accessibility Initiative guidelines) in their products and services. The inclusion of model language in publisher and vendor contracts specifically addressing accessibility requirements could have a significant impact if broadly adopted (see Appendix A for model language).

There are success stories in the marketplace to replicate. In early 2010, under a new system-wide technology accessibility initiative in the California State University (CSU) system, the CSU campuses rejected a bid from Blackboard Learning — then the most widely used learning management system among CSU campuses_citing lack of accessibility. In his February 2012 testimony before the Senate Committee on Health, Education, Labor and Pensions, Mark Turner, Director of CSU's Center for Accessible Media, stated that this experience was a "wake-up call" for the company, and that "subsequent to that RFP process, Blackboard ${ }^{\circledR}$ undertook a major accessibility review and remediation process for their product, culminating in an award by the National Federation of the Blind for its robust support for 
persons who are blind." 44

Libraries can also request (or require, if need be) that prospective vendors complete a Voluntary Product Accessibility Template (VPAT) form for their product to document in detail the extent to which their product complies with Section 508. Although VPAT forms are non-binding, they do provide a communication tool for libraries and vendors to talk about accessibility issues at a granular level. Compliance with Section 508 is required, but there is no substitute for reasonably proficient user testing, preferably by a person with print disabilities who is an typical user of her selected assistive technology. Several universities have protocols by which their disability services offices evaluate any software whose acquisition is being contemplated. Even in cases when vended products are not fully compliant, VPATs can be a useful tool for encouraging vendors to establish accessibility roadmaps for their non-compliant or partially accessible products.

\section{Library Website Accessibility}

Research libraries, indeed all of higher education, rely upon the web to present and make available extensive amounts of information and instructional e-content. The degree to which websites are accessible varies greatly from institution to institution. Most research libraries provide access to information resources online through a library-managed website presence. The typical library website includes a mix of library resource discovery tools, subject guides, links to licensed electronic resources, and information about library services. Standards exist to improve the accessibility of web content for people with disabilities. The World Wide Web Consortium (W3C) Web Accessibility Initiative (WAI) develops guidelines and provides resources for web publishers to improve web accessibility. The W3C WAI website includes a wealth of information on the topic of web accessibility, including specific standards such as the internationally recognized Web Content Accessibility Guidelines (WCAG) standard. Library administrators are strongly encouraged to assess and create a plan for improving the accessibility of their library website and supporting web applications.

To gain more clarity on current practice and opportunities to make websites more accessible, the US Department of Justice issued an Advance Notice of Proposed Rulemaking in 2010 regarding accessibility of information and services on the web. ${ }^{45}$

The DOJ intends to publish a Notice of Proposed Rulemaking concerning website accessibility based on comments filed in 2012. In several settlements, DOJ has required places of public accommodation to comply with WCAG 2.0 AA standards.

\section{Electronic-Book Readers}

The recent explosive growth in popularity of portable e-book readers in the consumer marketplace has led many libraries to consider lending e-book devices as a service. E-book readers can vary greatly in terms of their support of accessibility features. The most accessible devices include screen magnification, text-to-speech functionality, and navigation features enabling individuals with print disabilities to access the content natively. The pairing of accessible e-book formats with accessible reading devices is key.

E-book accessibility may involve as many as three different considerations: the accessibility of the content, the accessibility of the reading platform, and the accessibility of the device. Thus, even if the 
content is rendered in an accessible format like EPUB 3, it may be wrapped in digital rights management (DRM) software that prevents a device with screen-reader software from getting to the content. Similarly, even if the device and the content are accessible, if it is on a platform that is not, the book will not be accessible.

Libraries that are considering e-book device lending as a service are strongly encouraged to examine the current state of accessibility support in the e-book device marketplace and opt for lending devices that have accessibility features built-in.

\section{User Services}

Most research libraries have a designated liaison librarian who can provide or coordinate library assistance for users with disabilities in partnership with disability services offices, ${ }^{46}$ which typically handle curricular needs or materials serving as textbooks and are required for all students enrolled in courses. For some undergraduate courses, these materials may be sufficient for the course. Print-disabled students generally turn to the libraries for assistance with other needed materials, although disability services may play an intermediary or facilitator role.

Everyone who works at a library service desk, including temporary staff and part-time students, needs to be aware of how best to direct users with print disabilities for assistance. Since these positions can have regular turnover in many libraries, accessibility service awareness needs to be a standard part of staff training. Similarly, it is important to have user-focused policies and procedures that are readily available and kept up to date.

Not all those who may benefit from adaptive technology tools have access to these tools, in part due to economic factors or infrastructure requirements. Research libraries can, and many ARL member libraries do, provide access to adaptive technology tools as a library service within the physical library space. The prevalence of adaptive technology centers varies from one campus to the next. Many universities offer students access to adaptive technology equipment and support in a computer lab that is managed by the disability services office or the campus IT department. However, even with campus-wide support services, libraries can always add value by locating adaptive technology in the physical library space, since libraries are typically open much later than other buildings on campus. In such spaces, staff should be well trained in the use of this equipment and software.

The librarian liaison can consult with a student regarding what materials would be helpful and how best to make these resources accessible in light of his/her specific disability. Some libraries have designated staff to handle these requests, while others use departments that do all library scanning or technical support to provide these services. Students do not customarily give themselves much lead time on assignments, so having a policy and procedure in place to provide students with a reasonable expectation of the speed of handling these requests is critical.

Experience teaches us that some users would prefer to be able to do it themselves rather than have to ask for some additional service, and independence is a value research libraries routinely foster. For example, at UC Berkeley, the library provides 26 scanners throughout the system. Starting in fall 2012, students with print disabilities receive campus ID cards pre-loaded with funds for scanning. (Nondisabled students are charged for scanning.) These 26 scanners convert hard-copy print into electronic documents, in several digital format options, which the student can download onto a personal thumb 
drive to take home for their screen reader to read aloud via synthesized speech. For students who are print disabled and wish to self scan, UC Berkeley offers two locations with scanners where a synthesized speech software program has been installed.

There are many constituencies with print disabilities who have a wide range of information needs. Some students with learning disabilities may not require special equipment or software, but rather some special facilities arrangements. A student at one ARL institution requested quiet study space where she can read the text aloud without disturbing others. Most research libraries can deal with these kinds of requests, but it is useful to keep in mind that specific kinds of space may be the answer for some user needs.

Going forward, it will be important that universal accessibility be embedded in library and information products, which are licensed and acquired, so special conversion to a usable format will only be required for retrospective works. With born-digital texts, e-readers, and other mobile devices, research libraries must be strong advocates for accessible solutions up front—born-accessible materials—obviating the need for resource-intensive reformatting and retrofitting.

Although the focus of this report is on primary users, i.e., students, faculty, and staff, many publicly supported institutions also serve the public. However, in order to be eligible for special services or accommodations on campus, users with print disabilities need to self-identify and register with disability services. This registration process, and the desire among some to keep invisible disabilities undisclosed, likely means that there are more than the officially registered population who would benefit from a more inclusively designed physical and information environment.

\section{SIDEBAR: ONTARIO COUNCIL OF UNIVERSITY LIBRARIES (OCUL) REPOSITORY}

The OCUL Repository and Training Pilot serves as an example of large-scale collaboration and vision necessary to achieve equality of services for the print disabled.

In partnership with the University of Toronto, OCUL Scholars Portal received an Ontario government grant to explore an innovative approach that would allow students to more independently acquire the materials they need for study. The OCUL consortium received funding to pilot a project that would:

- Build a collective repository of digitized material held in libraries that had been requested by print-disabled students.

- Provide an authentication interface for registered print-disabled students that would allow them to directly access resources in this repository and, if something is not found, to generate a request.

- Develop workshops and tool kits for library staff so that they could more effectively change processes to improve library support for print-disabled students, for example, developing acquisition staff scripts for negotiating with vendors on purchasing and licensing accessible products, as well as requiring all staff to consider accessibility when developing new services and creating information pages on the web, etc. 
The OCUL project will provide an opportunity to explore the potential for success of this kind of service. If successful, more funds would be sought to expand and improve the new collaborative service. Ultimately, the program would be fully sustained by OCUL libraries that participate in the program.

In this first phase, taking full advantage of the Scholars Portal digital library infrastructure, at least four libraries will contribute alternative format materials to a repository that has the ability to authenticate disabled students that have self-identified and registered at each institution. These students may then search for and access materials from the repository. If something is not available, they may submit a request. Either the home institution will digitize the materials in-house or take advantage of the Internet Archive operation at the University of Toronto to digitize materials.

The goal is to reduce duplication of resources by retaining scanned copies for reuse in a digitally secure repository that allows self-service through a robust authentication system. The repository will contain alternative copies of materials held at OCUL libraries. The target is to have 1,000 items available by the end of the year-long pilot. 


\section{Universal Design, Inclusive Design, Accessibility, and Usability}

igital content cannot be assumed to be accessible to assistive or adaptive technologies such as text-to-speech screen readers. Early PDFs that still populate library websites and databases were often image-only files, and some software will not recognize columns in articles nor translate charts, graphs, and figures into something meaningful and accurate. Crowded database search screens with image-only buttons for critical navigation or access to full text have similarly been problematic. But even as some problems are solved, others are created if accessibility is not an upfront consideration. E-books are a key example.

The primary factors that have excluded visually impaired users from the e-book revolution are the use of file formats that cannot be read by the technologies used by the blind; DRM schemes that prevent such technology from accessing these files; and proprietary e-book reading software or devices that the blind cannot use. E-books, which hold the promise of truly equal access by the blind to all printed information, are in serious danger of becoming an even greater barrier to such access. ${ }^{47}$

In a Canadian study of students using screen readers to use popular library databases, the authors found significant barriers to discovery and full-text access.

Studies have shown that information literacy is a critical element in fostering problem solving and independent learning in higher education students...The question this study asked was whether the barriers in database design can affect a student's information gathering process. The results would point to yes, the first step in information literacythe ability to critically locate and select appropriate articles is being compromised. The students in our study were forced to abandon articles because of technological barriers and this limited the amount of resources they could use to write their assignments. Only the intervention of a librarian or peer would have allowed them to continue in locating the full text and reading the article. Their self-efficacy as independent learners is challenged every time they encounter an unreadable PDF or take up to eight hours to find four articles. ${ }^{48}$

Universal design is a concept that originated in architecture and the built environment. Perhaps its most cited example and metaphor is the curb cut, mandated and designed for wheelchairs but appreciated by anyone with a stroller, shopping cart, bicycle, or rolling suitcase. "Similarly, text captions of speech in videos were intended for individuals who are hard of hearing or deaf, but the primary users are patrons at noisy sports bars and fitness centers and spouses who wish to continue watching television while their spouse sleeps. In addition to being more sustainable, integrated accessibility features are also far less costly in the long run and, according to a study by Microsoft, are used by up to $67 \%$ of users." ${ }^{\prime \prime 9}$

Retrofitting technology, like architecture, is far more expensive than planning for inclusion by design. "The cost of accessibility when carefully planned and designed is almost zero...However, often extreme 
challenges and significant expense is involved in the process of retrofitting an existing website for accessibility." ${ }^{50}$

Universal design in instruction or learning (UDI or UDL), which first surfaced in K-12 education but has grown in post-secondary institutions, recognizes that designing the classroom for maximum inclusion of diverse learning styles and physical abilities, without sacrificing either standards or aesthetics, will bring unanticipated benefits to the entire population served. The information literacy movement has long recognized that diverse learning styles were important considerations in delivering effective library instruction to all students.

Experts in the field of universal design note many instances of accessible technologies leading true innovation and widespread adoption, including "the typewriter, the telephone, email, the PDA, speech synthesis and recognition. All these innovations were motivated by a need to address the needs of people with disabilities." ${ }^{11}$ IBM is an example of a successful corporate entity that has embraced accessibility by design as a successful marketing strategy for one of its largest consumers-the federal government. By corporate instruction, IBM trains its developers to "begin to focus on accessibility in the initial design stages and conduct assessments at key checkpoints in the development process." ${ }^{22}$ Academic leadership has also recognized the value of universal design, noting that universities would work to "make 'universal design' and accessibility part of the education that we provide to computer scientists and engineers at all levels-undergraduate, graduate and continuing education." 53

Unfortunately, as was the case with early website development, the opposite process can also prevail. ${ }^{54}$ "In the age of the Internet, the average time between the introduction of a new information technology and the availability of a version that is accessible to persons with disabilities is three years." ${ }^{55}$ To a student working toward degree completion, that is an unacceptable and effectively discriminatory length of time.

I've been told every year, “Oh, we're working on it,”...Well, you know, I've gotten to the point that I doubt it. I'm angry that something was put in place that was not verified. ${ }^{56}$ -Blind senior at the University of Montana, September 2012

As Thomas E. Perez, Assistant Attorney General of the Civil Rights Division, US Department of Justice, recently stated in regard to a new report on accessibility of US federal government information technology, “Technology and technological innovations can improve everyone's lives. However, if technology is not accessible, persons with disabilities can't benefit from those improvements." ${ }^{57}$ Perez also remarked on the high cost of retrofitting: "It is not terribly difficult or expensive to ensure that technology is accessible, but accessibility has often been an afterthought. Modifying existing technology to make it accessible is much more expensive than designing technology in an accessible manner in the first place." 58

In the virtual environment, some use the term "inclusive design" to distinguish the approach from the built environment, but make a similar claim that such design drives innovation for all users. If a platform, interface, space, or facility is equally accessible to all, it has the capacity to improve the experience and functionality for all. “Universal design focuses on eliminating barriers through initial designs that consider the needs of diverse people, rather than overcoming barriers later through individual adaptation. Because the intended users are whole communities, universally designed environments are engineered for flexibility and designed to anticipate the need for alternatives, options and adaptations to meet the challenge of diversity." 59 
Libraries and librarians do not need to become experts in every disability to meet the goals of universal or inclusive design. Rather, research libraries should advocate for content portability so that users can use the devices they prefer. A person with dyslexia might want to read text on a screen the size of a smart phone, a blind person might want that same content on a text-to-speech-enabled iPad. Research libraries should promote both portable content and discovery tools that can be effectively accessed by adaptive or assistive technologies.

In an open letter to all librarians, written in 2011, the President of the National Federation for the Blind, Marc Mauer, wrote: "Libraries can meet their obligations by adopting and publicizing accessibility policies; incorporating accessibility into their technology procurement, development, and testing processes; holding vendors accountable for accessibility; training staff; seeking input directly from patrons with disabilities; and conducting regular audits of accessibility." ${ }^{\prime \prime}$

The Canadian study of databases and screen readers concluded:

The digital collection of articles, books and resources provides greater access to resources 24/7 for our students. Various sectors are benefiting from digital access like distance education students and to a certain extent, students with print disabilities. While the print collection of a library is usually inaccessible to students with print disabilities, a database that can offer accessible features like simplified search screens will mean instant access to resources. As the digital information world continues to grow and offer more and more features for its users, it must also evolve to take into consideration the needs of these students. The Academic library and database vendors must work together, in consultation with students with print disabilities, to ensure technology opens up doors and tears down walls. To allow barriers to exist in this technological advanced age would prove to be the greatest failure of the twenty-first century library. ${ }^{61}$ 


\section{Conclusion}

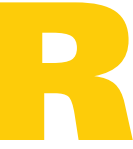

esearch libraries have an important opportunity to meet the urgent need to make information resources accessible to the print disabled, and in so doing, fulfill their mission to be content leaders in higher education and enhance information access to their users. The path forward requires planning and collaboration across the research institution, particularly with academic leadership, disability services offices, and information technology units. Accessibility is not only an ethical imperative; it is a legal requirement. Research libraries are a substantial market for digital information resources. While publishers, database vendors, and device manufacturers are not subject to federal and provincial accessibility law in their role as providers, libraries are subject to these laws and should demand the necessary design elements to serve the print disabled and all patrons equitably. With coordinated technology planning, procurement, and licensing, a fully accessible research library is a mission-critical goal that is within reach. 


\section{Appendix A: Model Licensing Language}

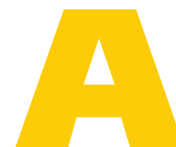

s libraries negotiate these terms it may be helpful to begin with reference to model language that has been proposed by several organizations. This language is designed to permit libraries to make content in their collections fully accessible. This model language is based on several existing model documents, including the Northeast Research Libraries Consortium Generic License, the California Digital Library Model License Agreement, the Ontario Council of University Libraries (OCUL) Draft Language for Model Licenses, and draft language developed by OCUL for local load agreements. Of course, this language should not be used uncritically as "boilerplate." Individual institutions should instead use this as a starting place to begin their own consideration of these issues.

\section{Model US License}

Licensor shall comply with the Americans with Disabilities Act (ADA), by supporting assistive software or devices such as large-print interfaces, text-to-speech output, refreshable braille displays, voiceactivated input, and alternate keyboard or pointer interfaces in a manner consistent with the Web Content Accessibility Guidelines published by the World Wide Web Consortium's Web Accessibility Initiative. Licensor shall provide Licensee current completed Voluntary Product Accessibility Template (VPAT) to detail compliance with the federal Section 508 standards. In the event that the Licensed Materials are not Accessibility compliant, the Licensee may demand that the Licensor promptly make modifications that will make the Licensed Materials Accessibility compliant; in addition, in such an event, the Licensee shall have right to modify or copy the Licensed Materials in order to make it useable for Authorized Users.

\section{Ontario Council of University Libraries (OCUL) Draft Language for Model Licenses}

\section{Definition-1.0 Accessible Formats}

Content must be perceivable and operable by persons with visual, perceptual, or physical disabilities and be useable with assistive devices, such as screen readers and screen reading software. Formats need to comply with the Accessibility Laws within Canada, including the Information and Communication Standards of Ontario Regulation 191/11, the Accessibility for Ontarians with Disabilities Act, 2005.

To address the requirements of the Act, web content must conform with the World Wide Web Consortium Web Content Accessibility Guidelines (WCAG) 2.0, initially at Level A and increasing to Level AA. ${ }^{62}$

\section{Persons with Visual, Perceptual, or Physical Disabilities}

Licensed Materials must be provided in a format accessible to Authorized Users with visual, perceptual, or physical disabilities. In the event that the Licensed Materials are not Accessibility compliant, as defined in 1.0, the Member Institution shall have the right to modify or copy the Licensed Materials in order to make it useable to Authorized Users, within the framework of this Agreement. 


\section{Endnotes}

1 A print-disabled person is someone who cannot effectively read print because of a visual, physical, perceptual, developmental, cognitive, or learning disability. Print is a proxy for textual "information"

in the research library environment, as research libraries collect in all formats for teaching, research, and learning.

2 The Library Copyright Alliance (LCA) consists of three major library associations-the American Library Association, the Association of Research Libraries, and the Association of College and Research Libraries. These three associations collectively represent over 300,000 information professionals and thousands of libraries of all kinds throughout the United States and Canada. These three associations cooperate in the LCA to address copyright issues that affect libraries and their patrons. The purpose of the LCA is to work toward a unified voice and common strategy for the library community in responding to and developing proposals to amend national and international copyright law and policy for the digital environment. The LCA's mission is to foster global access and fair use of information for creativity, research, and education.

3 “Joint 'Dear Colleague' Letter: Electronic Book Readers," DOJ and ED to College or University President, June 29, 2010, http://www2.ed.gov/about/offices/list/ocr/letters/colleague-20100629.html.

4 Legislative Summary of Bill C-11: An Act to Amend the Copyright Act, Library of Parliament Research Publication 41-1-C11E, Parliament of Canada, rev. April 20, 2012, http://bit.ly/Tr73LN.

5 “Inclusion Promotes Innovation," Jutta Treviranus, Toronto Star, Sept. 12, 2007, http://www.thestar. com/printArticle/255521.

6 "National Library Service: That All May Read: History," Library of Congress, Sept. 17, 2012, http:// www.loc.gov/nls/about_history.html.

7 In 1917, the name was changed to the Canadian National Library for the Blind, and in 1919 it became the Library and Publishing Department of the Canadian National Institute for the Blind.

8 Joseph W. Madaus, “The History of Disability Services in Higher Education,” New Directions for Higher Education, no. 154 (Summer 2011): 5-15.

9 In 1975, Congress passed the Education for All Handicapped Children Act of 1975 (PL 94-142), now called the Individuals with Disabilities Education Act (IDEA).

10 "An Open Letter on Accessibility from Research University Presidents," to President William J. Clinton, International Center for Disability Resources on the Internet, Sept. 20, 2000, http://www. icdri.org/DD/dd_universitystudy_letter_sen.htm.

11 Brian Wentz, Paul T. Jaeger, and Jonathan Lazar, "Retrofitting Accessibility: The Legal Inequality of After-the-Fact Online Access for Persons with Disabilities in the United States," First Monday, 
16 no. 11 (Nov. 7, 2011), http://firstmonday.org/htbin/cgiwrap/bin/ojs/index.php/fm/article/ view/3666/3077.

12 Government Accountability Office, Higher Education and Disability: Education Needs a Coordinated Approach to Improve its Assistance to Schools in Supporting Students, report GA-10-33 (Washington, DC: GAO, Oct. 2009), http://www.gao.gov/new.items/d1033.pdf.

13 "Participation and Activity Limitation Survey: Education Experiences of Children with Disabilities," Statistics Canada, May 27, 2008, http://www.statcan.gc.ca/daily-quotidien/080527/dq080527a-eng. htm.

14 Reading Rights Coalition, http://www.readingrights.org/.

15 “Vision Loss from Eye Diseases Will Increase as Americans Age," press release, National Eye Institute, National Institutes of Health, April 12, 2004, http://www.nei.nih.gov/news/ pressreleases/041204.asp.

16 "Making Museums and Libraries More Accessible," Institute of Museum and Library Services, Feb. 8, 2011, http://www.imls.gov/assets/1/AssetManager/Making\%20MusLibAccessible.pdf.

17 There have been two recent challenges to public library practices. The Department of Justice entered into a settlement agreement between the United States, the National Federation of the Blind (NFB), and the Sacramento (CA) Public Library Authority (August 28, 2012). The agreement found that the library's deployment of inaccessible e-readers violated Title II of the ADA. The library may no longer acquire non-accessible e-readers, is required to purchase accessible devices, and in the near future load these with content substantially equivalent to that on the inaccessible e-readers already in circulation and more. In May 2012, four blind patrons of the Free Library of Philadelphia, with the assistance of the NFB, filed suit against the library for providing inaccessible e-readers. The lawsuit has been resolved and the terms of the settlement call for the library to acquire 10 accessible e-readers to supplement the devices it has already purchased, and within four years to use only accessible e-reading devices. Finally, the library will include an accessibility requirement in its technology procurement contracts.

18 ADA Settlements and Consent Agreements, US Department of Justice, http://www.ada.gov/ settlemt.htm.

19 Ibid.

20 Ibid.

21 “Dear Colleague Letter," Office for Civil Rights, US Department of Education, May 26, 2011, http:// www2.ed.gov/about/offices/list/ocr/letters/colleague-201105-pse.html.

22 “University of Montana Students with Disabilities File Complaint over Inaccessible Online Course Components" Global Accessibility News, Sept. 18, 2012, http://globalaccessibilitynews. 
com/2012/09/18/university-of-montana-students-with-disabilities-file-complaint-over-inaccessibleonline-course-components/.

23 "Settlement between Penn State University and National Federation of the Blind," Pennsylvania State University, http://accessibility.psu.edu/nfbpsusettlement.

24 "Joint 'Dear Colleague' Letter: Electronic Book Readers," DOJ and ED to College or University President, June 29, 2010, http://www2.ed.gov/about/offices/list/ocr/letters/colleague-20100629.html.

25 Ibid.

26 Ibid.

27 "Electronic Book Reader Dear Colleague Letter: Questions and Answers about the Law, the Technology, and the Population Affected," Office for Civil Rights, US Department of Education, http://www2.ed.gov/about/offices/list/ocr/docs/504-qa-20100629.html.

28 Letter from Marc Maurer to Messrs. Lambert, Levitan, Waterhouse, and Dr. Oblinger, Sept. 12, 2012, http://net.educause.edu/ir/library/pdf/EPO1213/NFBE-Text\%20Sponsors9-12-12.pdf.

29 Letter from H. David Lambert and Diana G. Oblinger to Marc Maurer, Sept. 17, 2012, http://net. educause.edu/ir/library/pdf/EPO1213/Lambert-OblingerNFB\%209-17-12.pdf.

30 Report of the Commission on Accessible Instructional Materials in Postsecondary Education for Students with Disabilities (Washington, DC: The Commission, Dec. 2011), http://aim.cast.org/ collaborate/p-s_commission.

31 The Chafee Amendment is named after Senator John Chafee of Rhode Island, who long championed the rights of the print disabled. For the text of the amendment, see http://www.copyright.gov/ title17/92chap1.html\#121.

32 The Authors Guild, Inc. v. HathiTrust, No. 11-CV-6351 (HB), slip op. at 22-23 (S.D.N.Y. Oct. 10, 2012).

33 More information on these organizations can be found at: http://www.loc.gov/nls/; http://www. learningally.org/; http://nfb.org/libraries-for-the-blind; https://www.bookshare.org/; http://www. aph.org/.

3417 U.S.C. § 110(8), http://www.copyright.gov/title17/92chap1.html\#110.

3517 U.S.C. § 107, http://www.copyright.gov/title17/92chap1.html\#107.

36 Association of Research Libraries; Center for Social Media, School of Communication, American University; Program on Information Justice and Intellectual Property, Washington College of Law, American University; Code of Best Practices in Fair Use for Academic and Research Libraries (Washington, DC: ARL, Jan. 2012), http://www.arl.org/pp/ppcopyright/codefairuse/index.shtml.

37 HathiTrust at 22.

38 Page 1, Defendant Intervenors' Memorandum of Law in Support of Motion for Summary Judgment. 
39 The court cited the LCA brief in support of this finding.

40 Documents for WIPO Standing Committee on Copyright and Related Rights: Twenty-Fifth Session, Nov. 19-23, 2012, Geneva, Switzerland, http://www.wipo.int/meetings/en/topic.jsp?group_id=62.

41 Legislative Summary of Bill C-11: An Act to Amend the Copyright Act, Library of Parliament Research Publication 41-1-C11E, Parliament of Canada, rev. April 20, 2012, http://bit.ly/Tr73LN.

42 Ibid.

43 Ibid.

44 "Statement of Mark Turner, Director, Center for Accessible Media, California State University, Before the Senate Committee on Health, Education, Labor and Pensions, 'The Promise of Accessible Technology,"' Feb. 7, 2012, http://www.help.senate.gov/imo/media/doc/Turner3.pdf.

45 Current law requires that those places of public accommodation that have a physical presence must make services, such as websites, publicly accessible.

46 Suzanne M. Brown and LeiLani Freund, Services for Users with Disabilities, SPEC Kit 321 (Washington, DC: ARL, Dec. 2010), http://publications.arl.org/Services-for-Users-with-Disabilities-SPEC-Kit-321/.

47 Chris Danielsen, “Design and Public Policy Considerations for Accessible E-book Readers,” Interactions 18, issue 1 (2011), 68.

48 Kelly Dermody and Norda Majekodunmi, “Online Databases and the Research Experience for University Students with Print Disabilities," Library Hi Tech 29 no. 1 (2011), 149-160, http://www.hari. pitt.edu/Portals/0/Dermody\%202011.pdf.

49 Jutta Treviranus et al., "Levering Inclusion and Diversity as Canada's Digital Advantage,” Inclusive Design Research Centre, OCAD University, http://idrc.ocad.ca/index.php/resources/idrc-online/49articles-and-papers/453-leveraging-inclusion-and-diversity-as-canadas-digital-advantage.

50 Wentz, Jaeger, and Lazar, “Retrofitting Accessibility."

51 Treviranus, “Inclusion Promotes Innovation."

52 “IBM's Focus on Accessibility,” IBM, http://www-03.ibm.com/able/product_accessibility/ ibmcommitment.html.

53 "An Open Letter on Accessibility from Research University Presidents," to President William J. Clinton, International Center for Disability Resources on the Internet, Sept. 20, 2000. http://www. icdri.org/DD/dd_universitystudy_letter_sen.htm.

54 Kelly A. Harper and Jamie DeWaters, "A Quest for Website Accessibility in Higher Education Institutions," Internet and Higher Education 11 (2008), 160-164.

55 Wentz, Jaeger, and Lazar, "Retrofitting Accessibility." 
56 “University of Montana Students with Disabilities File Complaint,” Global Accessibility News.

57 “Justice Department Releases a Report on Accessibility of Federal Government Electronic and Information Technology" Sept. 12, 2012, http://www.justice.gov/opa/pr/2012/September/12-crt-1103. html.

58 Ibid.

59 David Rose, et al., “Universal Design for Learning in Postsecondary Education,” National Center on Universal Design for Learning, p. 2, http://www.udlcenter.org/resource_library/articles/ udl_postsecondary_ed.

60 “A Letter from Dr. Marc Maurer to All Librarians," National Federation of the Blind, July 29, 2011, http://www.nfb.org/a-letter-from-dr-marc-maurer-to-all-librarians.

61 Dermody and Majekodunmi, “Online Databases and the Research Experience,” 158.

62 “Web Content Accessibility Guidelines (WCAG) 2.0,” World Wide Web Consortium, Dec. 11, 2008, http://www.w3.org/TR/WCAG/.

(C) 2012 ARL

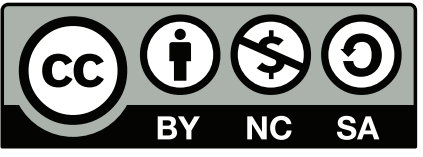

This report is licensed under a Creative Commons Attribution-Noncommercial-Share Alike 3.0 United States License. To view a copy of this license, visit http://creativecommons.org/licenses/by-nc-sa/3.0/us/.

To cite this report: Mary Case, et al. "Services to Patrons with Print Disabilities." Research Library Issues: A Quarterly Report from ARL, CNI, and SPARC, no. 281 (December 2012). http://publications.arl.org/rli281/. 


\section{Research Library Issues}

\section{A Quarterly Report from ARL, CNI, and SPARC}

Research Library Issues (RLI) focuses on current and emerging topics that are strategically important to research libraries. The articles explore issues, share information, pose critical questions, and provide examples. Ideas for articles are welcomed. Please send ideas to Sue Baughman, ARL Deputy Executive Director, sue@arl.org.

Association of Research Libraries

21 Dupont Circle, NW, Suite 800

Washington, DC 20036

P: 202-296-2296

F: 202-872-0884

ISSN 1947-4911

Executive Director: Charles B. Lowry

Editor: M. Sue Baughman

Assistant Editor: Kaylyn Groves

(C) 2012 Association of Research Libraries

ARL policy is to grant blanket permission to reprint for noncommercial use as long as full attribution is made. Exceptions to this policy may be noted for certain articles. This is in addition to the rights provided under sections 107 and 108 of the Copyright Act. For commercial use, a reprint request should be sent to ARL Publications pubs@arl.org.

Current and back issues are available on the ARL Digital Publications website publications.arl.org/rli. The website is also where you may sign up for alerts to new releases of Research Library Issues. 